\title{
The impact of new developments on river water quality from
}

\section{an integrated system modelling perspective}

\author{
Guangtao Fu*, David Butler and Soon-Thiam Khu \\ Centre for Water Systems, School of Engineering, Computing and Mathematics, \\ University of Exeter, North Park Road, Harrison Building, Exeter EX4 4QF, UK \\ *Corresponding author. Tel: +44 (0)1392 264075 Fax: +44 (0)1392 217965 \\ Email: G.Fu@exeter.ac.uk \\ D.Butler@exeter.ac.uk \\ S.T.Khu@exeter.ac.uk
}

\begin{abstract}
New housing areas are a ubiquitous feature of modern life in the developing and developed world alike built in response to rising social, demographic and economic pressures. Inevitably, these new developments will have an impact on the environment around them. Empirical evidence confirms the close relationship between urbanisation and ambient water quality. However, what is lacking so far is a detailed and more generalised analysis of environmental impact at a relatively small scale. The aim of this paper is to quantify the impact of new developments on river water quality within an integrated system modelling perspective. To conduct the impact analyses, an existing integrated urban wastewater model was used to predict water flow and quality in the sewer system, treatment plant and receiving water body. The impact on combined sewer overflow (CSO) discharges, treatment plant effluent, and within the river at various reaches is analysed by 'locating' a new development on a semi-hypothetical urban catchment. River water quality is used as feedback to constrain the scale of the new development within different thresholds in compliance with water quality standards. Further, the regional sensitivity analysis (RSA) method is applied to reveal the parameters with the greatest impact on water quality. These analyses will help to inform town planners and water specialists who advise them, how to minimise the impact of such developments given the specific context.
\end{abstract}

Key words: Integrated system modelling; new development; sensitivity analysis; Urban planning; urban wastewater system; water quality 


\section{Introduction}

Urbanisation has long been recognised as a principal contributory factor to many environmental problems, including flooding, biodiversity loss, deterioration of aquatic ecosystems and many others. These impacts usually come with modification of the natural hydrologic condition, increase in runoff pollutant loadings and wastewater discharge, and decrease in river base flow during dry weather, as a result of land cover change and intensified human activity due to urbanisation (Butler and Davies, 2004; Olivera and DeFee, 2007). In the urban planning process, the implications of new developments need to be fully addressed within the context of an entire urban catchment in order to achieve sustainable growth. Further, the best urban planning can only be achieved on the basis of a fuller understanding of the cause-effect relationships that drive environmental change, and interactions between man-made and natural systems that can be controlled to mitigate the potential impacts of new developments.

In recent years, the relationship between urbanisation and water quality of the surrounding surface water bodies has been extensively studied (e.g., Bhaduri et al., 2000; He et al., 2008; Duh et al., in press), and a strong relationship has been observed for many urban catchments. For example, the spatial and temporal variations of surface water quality in Shanghai, China, measured by an integrated pollution index, were significantly affected by the level of urbanisation between 1982 and 2005 (Wang et al., 2008). Van Dolah et al. (2008) confirmed that fecal coliform bacterial concentrations were positively correlated with urban land cover measures and negatively correlated with non-urban land cover categories in 29 estuarine watersheds of South Carolina, USA. Chang (2008) concluded that urban land cover was positively associated with increases in water pollution and identified as an important variable for the variations in 
water quality parameters, including temperature, dissolved oxygen (DO), biochemical oxygen demand (BOD), chemical oxygen demand (COD), suspended solids (SS), total phosphorus (TP) and total nitrogen (TN), through examination of 118 sites in the Han River basin of South Korea. In general, these studies used statistical analysis methods to identify the possible link between various aggregate land uses and water quality indicators measured over a relatively long period at a large scale. Only a few studies have been conducted at a relatively small scale considering characteristics of development such as housing density (Atasoy et al., 2006).

In the urban planning process, however, it is important to understand not only the relationships between urbanisation and water quality in general, but more specifically how development patterns (for example) may influence various water quality indicators so that potential environmental impacts can be mitigated. Simulation models have long been used as valuable tools for prediction of the flow and quality of receiving waters in the environmental and water engineering fields (Butler and Davies, 2004), and thus can best assess the far-reaching effects of various planning and management options. For example, Choi and Deal (2008) integrated a land use model with a semi-distributed hydrological model to quantify the impact of potential land use changes on river flow. As receiving water quality typically is deteriorated during rainfall events in urban catchments, this paper takes an innovative and completely different approach, by using an integrated simulation model of urban wastewater systems, to examine the impact of development patterns of new housing areas on river water quality.

Conventional urban water management practice considers the sewer network, treatment plant, and river as separate systems, however, in recent years, newer integrated system modelling approaches have been developed which enable the interactions between the individual components to be dynamically represented (Schütze 
1998; Rauch et al., 2002; Vanrolleghem et al., 2005; Achleitner et al., 2007). These integrated approaches have been mainly used to demonstrate, in combination with optimisation tools, the potential beneficial impact of real time control of the integrated system on river quality, and also applied for analysing various scenarios with regard to source control, engineering measures, and system operation (Rauch and Harremoës, 1999; Schütze et al., 2004; Butler and Schütze, 2005; Fu et al., 2008).

The aim of this paper is to quantify the detailed impact of new developments on receiving water quality using an integrated urban wastewater model. A new housing area is 'located' in an existing urban catchment, different sizes and types of which are tested based on planning parameters such as population size and housing density. Receiving water quality is assessed using the model for different planning scenarios in terms of a number of indicators. Inversely, the impact of different water quality standards is established to provide an insight into feasible development sizes and patterns that comply with legislative constraints. The sensitivity of planning parameters is analysed to improve understanding of the key urban planning factors associated with water environment impact.

The paper is structured as follows: description of the integrated model and sensitivity analysis methods are presented in Section 2. Section 3 depicts the urban catchment used to conduct the impact analysis. The parameters for planning the new development are introduced in Section 4 and water quality indicators for quantifying the environmental impact in Section 5. The results are presented and discussed in Section 6. Finally, concluding remarks are given in Section 7. 


\section{Methodology}

\subsection{Integrated urban wastewater model}

The integrated model was developed using the commercial tool SIMBA 5.0 from IFAK system GmbH, Germany. This tool provides a library of blocks for the sewer system, treatment plant and river sub-systems in the MATLAB/SIMULINK environment, which allows users to build models graphically by dragging, dropping and linking selected blocks. The integrated model is structured to simulate various hydraulic and biochemical processes of the three sub-systems in a single simulation environment, which enables consideration of the dynamic interactions between these sub-systems.

The sewer system is represented in a similar way to the KOSIM model (ITWH, 1995). The processes considered include surface runoff and wash-off, flow and pollutant transport in sewers and storage tanks. Surface runoff in impervious and pervious catchment areas is simulated separately. For the former, wetting, depression storage, and evaporation losses are taken into account, and for the latter, a modified Horton approach for long-term simulation is used for modelling infiltration. Flow transport within a sub-catchment is simulated by using a cascade of $c$ linear reservoirs with each reservoir described by the storage equation

$S(t)=K Q(t)$

and the continuity equation

$$
\frac{d S(t)}{d t}=I(t)-Q(t)
$$

where $S(t)\left[\mathrm{m}^{3}\right], Q(t)\left[\mathrm{m}^{3} / \mathrm{s}\right]$ and $I(t)\left[\mathrm{m}^{3} / \mathrm{s}\right]$ are storage, outflow, and inflow at time $t$, respectively, and $K[\mathrm{~s}]$ is a storage constant.

Pollutants simulated in the sewer system include SS, volatile suspended solids (VSS), COD, soluble COD, ammonium and nitrate. Although the characteristics of pollutants 
from stormwater are of high spatial and temporal variability (Kafi et al., 2008), constant values are assumed for pollutant concentrations of runoff in this study for simplicity and this is thought appropriate for impact analysis. Storage tanks of different types are also considered and these can be controlled via outlet pumps.

Activated Sludge Model No.1 (ASM1) was chosen to model wastewater treatment because it is generally accepted as the state-of-the-art in simulating municipal activated sludge wastewater treatment plants (Henze et al., 1986). This model has been included in many simulation platforms for wastewater treatment processes and control optimisation, and is included in the Benchmark Simulation Model No.1 by an IWA Task Group (Copp, 2002). The sedimentation tanks are modelled by the onedimensional layered settler of Takács et al. (1991) because of its international acceptability.

The river is simulated using the EPA storm water management model (SWMM), which is one of the most advanced computer models for hydrodynamic simulation of water and pollutant transport in sewer systems. In SIMBA 5.0, SWMM is encapsulated into a block to simulate the sewer system or river. This enables a fully dynamic simulation of river flow, which is necessary to model the impact of CSO discharges and treatment plant effluent. SIMBA 5.0 offers the facility for SWMM to represent various biochemical transformation processes in a water quality model using a matrix format. The river water quality model used herein was described by Schütze (1998). Pollutants considered include readily and slowly biodegradable BOD, ammonium and DO.

How to deal with the pollutant sets used in the three sub-systems is a key problem in the context of integrated modelling, and it has a great effect on model performance and reliability. While developing consistent pollutant sets for various sub-systems still has some difficulties, a factors-based conversion method is usually used to convert the 
different pollutant sets between various sub-systems in the integrated model (Rauch et al., 2002), and this method is also adopted by the WEST simulation tool (Vanhooren, et al., 2003). The conversions described by Schütze (1998) are used in this integrated model.

\subsection{Regional sensitivity analysis}

The aim of sensitivity analysis is to evaluate the effect of model parameters on overall model performance (as indicated by water quality indicators) and thus reveal the most influential parameters. There exist a number of sensitivity techniques, which can be broadly classified as local or global approaches (Saltelli et al., 2006). In a local analysis, the model is perturbed one parameter at a time whilst the others are fixed to a nominal value. The local approaches can only be justified for linear models (Saltelli et al., 2006). Furthermore, the results become less reliable when the perturbation moves further away from the nominal value. However, in a global analysis, all the parameters can vary simultaneously aiming to exploring the parameter space within a finite region. Thus, the interaction between parameters can be taken into account, which means that the measure of regional sensitivity for each parameter is not only dictated by the model response to a unit perturbation in that parameter, but by the relative responses due to all the factors. So in this study, a reliable global approach, Regional Sensitivity Analysis (RSA) by Hornberger and Spear (1981), is chosen for the integrated urban wastewater model, exhibiting high-dimensional, non-linear behaviours.

The main idea of RSA is the division of model objective space into behavioural or non-behavioural region in terms of a priori defined criteria. The procedures can be described as follows: 
1. Generating parameter sets through a sampling technique, such as Monte Carlo method. An importance sampling variance of the Monte Carlo method, Latin Hypercube Sampling (LHS), is used in this study to improve sampling efficiency and thus reduce the number of simulations necessary for obtaining reliable results.

2. Evaluating the objectives for each of the parameter sets using a Monte Carlo procedure, and classifying as being either a behaviour (B) or non-behaviour (NB) according to the ranking of the chosen objective, using a priori defined criterion. For a multi-objective analysis, this classification needs to be conducted for each objective separately.

3. For both behavioural and non-behavioural groups, each of the parameter sets is assigned a likelihood using a subjectively chosen likelihood function regarding each of the objectives. The cumulative marginal distribution of each parameter for each objective is then derived in terms of the likelihoods.

The difference between the two cumulative marginal distributions can be summarised by using a two-sample Kolmogorov-Smirnov test (KS test). The statistic $D_{m, n}$ is determined as the maximum vertical distance between the cumulative distribution curves for behaviours and non-behaviours:

$$
D_{m, n}=\sup _{x}\left|S_{B}(x)-S_{N B}(x)\right|
$$

where $S_{B}$ and $S_{N B}$ are the empirical distribution functions for $n$ behaviours and $m$ nonbehaviours samples, respectively. The statistic is sensitive not only to differences in central tendency but also to any difference in the distribution functions. Accordingly, the significance of the statistic indicates the importance of that parameter in terms of the specific objective. Thus, the larger the value of $D_{m, n}$, the more important the parameter. 
RSA has been widely applied in the fields of environmental and hydrological modelling (McIntyre et al., 2003; Cox and Whitehead, 2005), and provides a theoretical foundation for the development of the generalised likelihood uncertainty estimation method (Beven and Binley, 1992).

\subsection{Latin hypercube sampling}

LHS is designed to accurately recreate a distribution through fewer samples compared with a pure random sampling. To achieve this, a 'stratification' technique is used to divide the cumulative probability from 0 to 1.0 into equal intervals, usually one for each simulation in a Monte Carlo procedure, from which a sample is randomly taken. Sampling is thus forced to represent values in each interval. When sampling from multiple variables, the independence is maintained by randomly selecting the interval for each variable to form a parameter set. LHS ensures optimum coverage of the individual parameter ranges, and 10,000 parameter sets are sampled in this study to give relatively comprehensive representation of two-, three-, and four-factor interactions (McIntyre et al., 2003).

\section{The integrated urban catchment}

The catchment used in this study was first defined by Schütze (1998) and has been studied in detail for real time control problems (Lau et al., 2002; Butler \& Schütze, 2005; Fu et al., 2008). It consists of a sewer system, a treatment plant based on real systems to some extent and a hypothetical river system, as shown in Fig. 1.

The sewer system originated from a German example, and was adapted to match the capacity of the treatment plant described below. It has seven sub-catchments, whose characteristics are shown in Table 1. There are four on-line pass through storage tanks, 
located at the downstream of the sub-catchments $2,4,6$, and 7 . The outflow of each of the four tanks is controlled by a pump.

To facilitate the impact analysis, a new sub-catchment, SC8 as shown in Fig. 1, is assumed to be designated as the new development area, and is situated downstream of SC5. The aim of the study is to investigate the impact of developing new housing in SC8 for up to 20,000 residents, $13 \%$ of the existing population. The new development has a variable area depending on the population size and two other planning parameters, i.e., housing density and housing occupancy. The parameters of the reservoir cascade are regarded as the same as SC5.

Suitable concentrations for dry weather flow and stormwater in this case study are chosen from the dataset given by Lessard (1989), as follows: for dry weather flow, SS: 335 mg/l; VSS: 245mg/l; COD: $606 \mathrm{mg} / \mathrm{l}$; soluble COD: $281 \mathrm{mg} / \mathrm{l}$; ammonium: 27.7 mg/l; nitrate: 0; for stormwater, SS: $190 \mathrm{mg} / \mathrm{l}$; VSS: $139 \mathrm{mg} / \mathrm{l}$; COD: $100 \mathrm{mg} / \mathrm{l}$; soluble COD: $46 \mathrm{mg} / \mathrm{l}$; ammonium: $2 \mathrm{mg} / \mathrm{l}$; nitrate: 0 . Considering the variations of dry weather flow and its concentrations, diurnal patterns from Lessard (1989) are used herein.

The wastewater treatment plant is based on the Norwich sewage networks in eastern England and was studied in detail by Lessard and Beck (1993). This treatment plant has the capacity to treat an average dry weather flow of $27,500 \mathrm{~m}^{3} / \mathrm{d}$, and consists of a storm tank, primary clarifier, and activated sludge reactor and secondary clarifier. The tank, with a volume of $6750 \mathrm{~m}^{3}$, is an offline pass through storm tank, in which the particulate pollutants may settle before being discharged to the receiving river when overflows occur during rain events. This provides additional storage to that of the tanks in the urban sewer system. The waste and return activated sludge are taken from the secondary clarifier, and their flow rates are set to $660 \mathrm{~m}^{3} / \mathrm{d}$ and $14,400 \mathrm{~m}^{3} / \mathrm{d}$, respectively. 
The river system of concern is $45 \mathrm{~km}$ in length and is equally divided into 45 reaches for simulation, i.e., $1 \mathrm{~km}$ for each reach. In order to simulate the impact of treatment plant effluent and CSO discharges on the river water quality, the river base flow was set to be low at $129,600 \mathrm{~m}^{3} / \mathrm{d}$. This results in a 1:5 dilution ratio of dry weather treatment plant discharges to river base flow. Upstream catchment runoff generated by rainfall events is modelled as additional inflow into the river at reach 4. The CSOs discharges are assumed to be at reach 7 , and storm tank overflows and treatment plant effluent at reach 10 . The boundary conditions for concentrations are defined as the 'dry' scenarios used by Schütze (1998), as follows: ammonium: $0.09 \mathrm{mg} / \mathrm{l}$; DO: $9.0 \mathrm{mg} / \mathrm{l}$; slowly biodegradable BOD: $1.80 \mathrm{mg} / \mathrm{l}$; and readily biodegradable BOD is set to zero, assuming the organic material has biodegraded upstream of the treatment plant effluent and CSO discharges.

\section{Planning parameters}

The development pattern of a new housing area is defined by a number of parameters, which need to be decided in the planning stage. The planning parameters considered in this study are population size, housing density, housing occupancy and per capita water consumption.

\subsection{Population size}

The population size is the most important parameter to be decided in the planning stage. It has a direct relationship with the size of development area, affected by some parameters, for example, housing density and occupancy. It basically determines the development scale of the catchment, i.e., how much land needs to be set aside for urban use. Therefore, population size has a great effect on the percentage imperviousness of 
the whole catchment, and thus on the runoff processes. Meanwhile, population size is an important parameter affecting the total volume of discharged domestic wastewater in the sewer system.

\subsection{Housing density}

Housing density is one of the key parameters in development planning, which will define the percentage impermeable area of a catchment such as roads, roofs, parking places, driveways and other paved surfaces. Thus, this parameter, usually measured by the number of dwellings per hectare, has a significant effect on the rainfall runoff process as it closely relates to the percentage imperviousness $(P I)$ of the catchment.

An empirical relationship between housing density and PI was reported by Butler and Davies (2004):

$$
P I=6.4 \sqrt{J}
$$

where $J$ [dwelling/ha] is the housing density. Although this relationship was originally established for densities in the 10 to 40 dwellings per hectare range, it is assumed to be appropriate for high densities up to 100 dwellings per hectare in this work. The case study catchment described in Section 3 has an average of the housing density of 80 dwellings per hectare, which is regarded as the nominal value for the new development in this study.

\subsection{Housing occupancy}

Housing occupancy, also referred to as household size, is measured by the number of people per household. In recent years, a declining average housing occupancy has been observed in the developed countries. For example, according to the General Household Survey in Great Britain, the average household size declined from 2.91 persons in 1971 
to 2.31 persons in 2002, and the proportion of one-person households almost doubled from $17 \%$ to $31 \%$ between 1971 and 1998 .

\subsection{Per capita water consumption}

There is a strong link between water consumption and wastewater discharge at the household level, with relatively little supplied water being 'consumed' or taken out of the system. It is estimated that, in the UK, about $95 \%$ of water used is returned to the sewer network (Butler and Davies, 2004). This ratio is adopted in this study. The advances in domestic appliances, for example, less water is required for WC flushing, and increasing use of greywater and greenwater in practice, can help to reduce water consumption per capita.

The impact of these parameters is investigated within a wide range shown in Table 2 , drawn from social statistics and practical experience. Uniform probability distributions were used in the LHS procedure to draw the parameter sets for sensitivity analysis. This ensures that each parameter value has an equal chance to be chosen across its full range.

There are some other factors that could also have an effect on water quality in the surrounding water environment, for example, development location, construction of additional storage in the sewer system, improvement of the treatment capacity and efficiency, and application of different control strategies. Due to the complexity of each of these factors, they will not be included in this study but will be for future research instead.

\section{Water quality indicators}

Representing the urban wastewater system as a holistic system offers the chance to evaluate system performance directly with regard to receiving water quality indicators. 
The advantage has been demonstrated in 'water quality-based control' of urban wastewater systems (Rauch and Harremoës, 1999; Butler and Schütze, 2005; Vanrolleghem et al., 2005). In this study, a number of water quality indicators from receiving river, treatment plant effluent, and CSO discharge are used to assess the impact of new development.

Minimum river DO concentration (denoted by DO-M) and Maximum ammonium concentration (AMM-M) are used in this study as a proxy for overall river 'health'. When the DO concentration drops below a critical threshold or ammonium concentration exceeds a critical threshold, their duration of breaching such a threshold becomes more of a concern in terms of protection of aquatic life. Thus, the duration of DO and ammonium concentrations, denoted by DO-DU and AMM-DU, respectively, are also considered for impact assessment and defined as the percentage of the total simulation time. To calculate the DO-DU and AMM-DU, critical thresholds are chosen as $4 \mathrm{mg} / \mathrm{l}$ and $3.5 \mathrm{mg} / \mathrm{l}$, respectively, according to the Urban Pollution Management (UPM) Manual (FWR, 1998).

In a combined sewer system, stormwater flows into sewer networks and is mixed with wastewater during rain events, and the combined wastewater flows exceeding treatment capacity are diverted into receiving waters directly. Since Harremoës (1982) first reported the delayed impact of CSO discharges on oxygen concentrations, it has been widely recognised that CSO discharge is a significant pollution source and can pose a serious impact on water quality of receiving waters and aquatic environment (Butler and Davies, 2004; Chen et al., 2004; Even et al., 2007). The discharge volume is usually used as an objective to control the sewer system or treatment plant in an integrated urban wastewater system. Further, the discharges from the storm tank as shown in Fig. 1 are controlled to improve the performance of the treatment plant. Thus, 
these two discharges are chosen as an indicator in this study to assess the impact of new developments on the existing sewer system.

Treatment plant effluent quality is stringently regulated against consent standards, which are based on statistically checking the compliance of routine samples against quality criteria (usually 90 or 95 percentile). So 95th percentiles of SS, COD and ammonium, denoted as $95^{\text {th }} \mathrm{SS}, 95^{\text {th }} \mathrm{COD}$, and $95^{\text {th }}$ AMM, respectively, are considered as indicators to assess water quality of treatment plant effluent.

\section{Results and discussion}

\subsection{Simulation of base case scenario}

The base case scenario represents the 'business as usual' of the current urban wastewater system, without any new development built in the urban catchment. The integrated model was run for a six-day rainfall event from 7-13th February 1977, as shown in Fig. 2a, with a total depth of $27 \mathrm{~mm}$. All the controllers in the system are set to the default value defined by Schütze (1998).

Some CSO discharges are observed in Fig. 2b, which means that the maximum influent to treatment plant has been reached during this rainfall event. The treatment plant performance has deteriorated as suggested in Fig. $2 \mathrm{c}$ by the significant increases in COD and SS concentrations, and a slight increase in ammonium concentration in the treatment plant effluent. The periods of these increases correspond well to those of actual rainfall occurring. Fig. $2 d$ shows DO concentrations at various reaches in the receiving river, including Reach 7 at the downstream of CSO discharges, Reach 10 at the downstream of the treatment plant effluent, Reach 20 amongst the middle of reaches, and Reach 45 at the end of the simulated river. The effect of CSO discharges is clearly indicated at Reach 7, with the obvious deterioration of DO concentration. Further, the 
overall effect of CSO and treatment plant discharges is amplified as the polluted 'plugs' move downstream, caused by the degradation of discharged organic matter that exerts an oxygen demand in the river.

\subsection{Impact of population size}

In this analysis, the model was run with varying population sizes of up to 20,000 for the new development (SC8). The planning parameters are fixed at their nominal values as shown in Table 2. Fig. 3 shows the impact of the new development on water quality with respect to the indicators given in Section 5.

It can clearly be seen in Fig 3a that DO-M deteriorates continuously from the base case scenarios of $3.43 \mathrm{mg} / \mathrm{l}$ to $2.44 \mathrm{mg} / \mathrm{l}$ as the size of population increases, a steeper slope appears when the population is bigger than 5,000. Similarly AMM-M remains roughly the same until the population reaches 5,000 and then increases at a relatively rapid rate. It seems that the population size 5,000 acts as a critical point for the investigated urban wastewater system in terms of DO-M and AMM-M, after which both DO-M and AMM-M deteriorate at an increased rate. For the duration objectives in Fig $3 \mathrm{~b}$, the DO-DU is raised about 4 times longer when the new subcatchment is fully developed to a population of 20,000 and AMM-DU is also raised by $4 \%$.

Fig. $3 \mathrm{c}$ shows that the treatment plant has a consistent performance responding to the varying population size. The changes in the 95th percentile of SS and ammonium concentration are small while there is a noticeable change in COD. This is not surprising considering that the influent to the treatment plant is controlled and overflows are discharged into the receiving river directly through CSOs.

Volumetric discharges of both the CSO and storm tank experience a gradual increase across the whole population range, as shown in Fig. 3d. Considering the consistent performance of the treatment plant, it can be concluded that overflows are the main 
contribution to the continuous deterioration of DO and ammonium concentrations in the river, as indicated by DO-M, DO-DU, AMM-M and AMM-DU. This further confirms earlier work (Butler and Davies, 2004; Even et al., 2007).

Generally, the impact on various water quality indicators could be reduced by applying integrated control of sewer system and treatment plant. Further discussion of this issue is out of the scope of this paper and the reader is referred to Schütze (1998), Butler and Schütze (2005), and Fu et al. (2008).

\subsection{The maximum feasible population size}

Fig. 3a allows derivation of the maximum feasible population size for a new development to achieve compliance with a specified water quality standard. For example, if a DO concentration threshold of $3.0 \mathrm{mg} / \mathrm{l}$ is chosen, the maximum feasible population size must be approximately 9,000, to avoid breaching the critical water quality threshold. In this case, the population size is related to the default housing density, i.e., 80 dwellings/ha. When the above analysis is extended to the range of housing densities shown in Table 2, an upper bound curve of population size can be generated for the specified water quality threshold of $3.0 \mathrm{mg} / \mathrm{l}$. A number of such curves for different thresholds are shown in Fig 4.

Fig. 4a shows the effect of different housing densities and DO concentration thresholds on population size. Each curve, under which the development scale is within the environmental limit, represents the population capacity for a range of housing densities, given a specific threshold $\tau$. If the minimum allowable DO concentration is set to $3.4 \mathrm{mg} / \mathrm{l}$, the maximum supportable population is just between 1000 and 1,500, regardless of the housing density for the new development. When the DO threshold is reduced just slightly to $3.3 \mathrm{mg} / \mathrm{l}$, the maximum population is raised substantially to the range of 3000 to 5,500 depending on the housing density. This is illustrated by the big 
gap between the two adjoining curves $\tau=3.4 \mathrm{mg} / \mathrm{l}$ and $\tau=3.3 \mathrm{mg} / \mathrm{l}$. This gap is related to the shaded area in Fig. 4a, in which the population is between 1300 and 5,000 for the case of housing density 80 dwellings/ha as shown in Fig. 3a. In this area, a slight variation in threshold levels has the greatest impact on the population capacity. In other words, the population size has the least impact on the DO concentrations. In this specific catchment, the sewer system and treatment plant has a better capacity to cope with the impact of the population increase up to around 5,000, indicated by a slower DO deterioration compared with the DO changes for a larger population. Therefore, this area should be identified as 'preferable' and be given more consideration at the planning stage.

For the thresholds $(3.3-2.6 \mathrm{mg} / \mathrm{l})$, lowering the DO threshold would cause less impact on the maximum population compared to that when the DO threshold is set at $3.4 \mathrm{mg} / \mathrm{l}$. For example, given the specific housing density 80 dwellings/ha, the population capacity could be raised by 1,500 by moving to a lower threshold. However, the housing density has a more significant impact on the supportable population size for a lower threshold level, represented by the increased gradient for a lower threshold curve.

A similar relationship can be developed in terms of ammonium concentrations, as shown in Fig. $4 \mathrm{~b}$ for a range of ammonium thresholds from 3.9 to $4.4 \mathrm{mg} / \mathrm{l}$. A similar big gap is observed between the curves $\tau=3.9 \mathrm{mg} / 1$ and $\tau=4.0 \mathrm{mg} / 1$, which can allow for more uncertainty in planning the maximum population size. Housing density has more impact on the maximum population size for a higher ammonium threshold value.

In practice, when choosing a threshold level consideration might need to be given to the requirements of aquatic environment, water quality management targets, and legislative standards. For example, minimum DO levels of 3.0-3.5 mg/l are required to 
sustain cyprinid fisheries according to the UPM Manual (FWR, 1998), depending on the duration and frequency of the rain event. Considering various water quality indicators, planning the development scale in terms of population size is actually a multiple criteria decision making process, in which it is necessary to consider the trade-off between different objectives. However, understanding the maximum population curves in Fig. 4, which provide evidence on how the environmental limits affect the possible maximum scale for the new development, will help decision makers to make more informed, transparent decisions.

\subsection{Sensitivity analysis}

The parameter sets were divided into two groups in terms of the ranking of each of the objectives, and the cumulative distribution of each group was plotted for each parameter. Fig. 5 shows the results for DO-M only. Theoretically, the diagonal line (' $D$-line') indicates the parameter has a uniform distribution and the model is not sensitive to this parameter in terms of the chosen likelihood measure. Any departure from the ' $D$-line' shows a non-uniform distribution and the model is sensitive to this parameter as can be seen from Fig. 5. There is no statistically significant separation for housing occupancy, which means that this parameter is not important in controlling river DO concentrations. However, all the other three parameters exhibit an obvious mean shift. The cumulative distributions for housing density show that the values at the higher end of the tested ranges contribute to the greatest number of behaviours in terms of DO-M, i.e., higher housing densities lead to a higher DO-M. Conversely, the greatest number of behaviours occurs at the lower end of the range for water consumption. For population size, the greatest number of behaviours comes from values at the lower end of the range and the greatest number of non-behaviours from the higher end. Meanwhile, the 
population size has much more impact on DO-M, with the greatest shift from the straight line in comparison with the others.

The parameter sensitivity analysis was also conducted for all the objectives used in this study, and the KS statistic of each parameter that is significant above the $95 \%$ level for each objective is summarised in Table 3. It can be seen that population size is the most sensitive parameter for all objectives, followed by per capita water consumption. Thus, the population size for a new development is the most important parameter that needs to be carefully decided in terms of river water quality. This also confirms the importance of reduction of the wastewater discharged at the household level, which can be achieved by choosing water efficient appliances and applying suitable recycling technologies. Housing density and occupancy have a relatively small, mixed impact on the water quality indicators. In general, housing density has a greater impact on CSO overflows and river DO and ammonium concentrations than housing occupancy. Conversely, housing occupancy has a greater impact on treatment effluent concentrations.

\subsection{Parameter correlations}

Although the KS statistic provides an insight about the distinction between the behavioural and non-behavioural distributions, it may not identify the regional sensitivity hidden by high correlation between parameters. So the results of the RSA should be interpreted in conjunction with the parameter covariance or correlation matrix (McIntyre et al., 2003).

Table 4 shows the correlation coefficients between the parameters with magnitudes greater than 0.1 , on the basis of the behavioural samples with regard to each of the objectives. Most of these values indicate a negative correlation between population size and the other parameters. This reveals the interactions that one parameter of the pair 
might increase to a higher value if the other takes on a relatively lower value while still achieving the same water quality standards. Furthermore, the dominating relationships are between the pair of water consumption and population size, with a minimum magnitude of -0.372 observed for all the objectives except CSO volume. Fig. 6 shows their relationship for the top $20 \%$ behaviours, whose AMM-M values are less than a threshold of $4.07 \mathrm{mg} / \mathrm{l}$. Population can be increased to some extent if water consumption is reduced to a certain level while keeping AMM-M below 4.07 mg/l. Fig. 6 also shows that it is impossible for the combinations of a large population and high water consumption to maintain the ammonium concentration below the threshold, revealed by the empty space in the upper left hand corner of the plot.

As for CSO volume, positive correlations exist between house density (and occupancy) and population size, which mean that one parameter is likely to be low and if the other is low. A relatively weak correlation exists between water consumption and population size regarding this objective.

\section{Conclusions}

This paper investigated, by using an integrated urban wastewater model, the impact of new developments on CSO discharges and water quality in treatment plant effluent and within the river at various reaches for a specific case study site. The conclusions are summarised as follows:

- The population size of new developments has a significant impact on receiving water quality, measured by the objectives of DO and ammonium concentrations (DO-M, DO-DU, AMM-M, and AMM-DU). A significant deterioration could be caused by the increase in population size, while the overall 'capacity' of the urban wastewater system is approached. Finding out the crucial point is of 
significance in understanding the implication of new developments on the aquatic environment.

- It has been demonstrated that the continuous increase in CSO and storm tank discharges probably is the reason for river water quality deterioration in terms of DO and ammonium concentrations (DO-M, DO-DU, AMM-M, and AMM-DU). Thus, it is of significance to reduce CSO and storm tank discharges in order to maintain river water quality during rain events.

- There is little impact of new development on treatment plant effluent in terms of the $95^{\text {th }}$ percentile of COD, SS, and ammonium concentrations, possibly because the maximum influent to the treatment plant is controlled and excessive flows are discharged into the receiving river directly through CSOs in this study.

- To comply with water quality standards, it is necessary to understand the maximum feasible scale of new developments in terms of population size. A number of curves for the maximum population size have been developed for a variation of housing density, constrained by various DO and ammonium water quality thresholds. These curves provide an insight for planners and water specialists in understanding environmental capacity for a specific urban catchment.

- The regional sensitivity analysis method was used to analyse the sensitivity of model performance (represented by 8 water quality indicators) to the planning parameters, i.e., population size, housing density, housing occupancy, and water consumption par capita. The results reveal that the population size has the greatest impact on all water quality indicators, followed by water consumption. Housing density and occupancy have a relatively small, mixed impact. This 
provides a justification for adopting water saving and recycling measures at the household level in order to reduce the impact on river water quality.

These analyses could readily be implemented for in practice, and the results will help to inform planners and water specialists who advise them, to minimise the impact of such developments given the specific context.

\section{Acknowledgements}

This work was partly funded by UK EPSRC grants (GR/S86846/01 and GR/S18373/02), and was also supported by the Integrative Systems and the Boundary Problem project [www.tigress.ac/isbp], funded by the EU's Framework 6 Programme.

\section{References}

Achleitner S, Möderl M, Rauch W. CITY DRAIN (C) - An open source approach for simulation of integrated urban drainage systems. Environ Model Softw 2007; 22(8): 1184-1195.

Atasoy M, Palmquist RB, Phaneuf DJ. Estimating the effects of urban residential development on water quality using microdata. Journal of Environmental Management 2006; 79(4): 399-408.

Beven KJ, Binley A. The future of distributed models: model calibration and uncertainty prediction. Hydrol Proces 1992; 6: 279-298.

Bhaduri B, Harbor J, Engel B, Grove M. Assessing watershed-scale, long-term hydrologic impacts of land-use change using a GIS-NPS model. Environmental Management 2000; 26 (6): 643-658.

Butler D, Davies JW. Urban Drainage, 2nd edition, Spon Press, London, 2004. 
Butler D, Schütze M. Integrating simulation models with a view to optimal control of urban wastewater systems. Environ Model Softw 2005; 20: 415-426.

Chang H. Spatial analysis of water quality trends in the Han River basin, South Korea. Water Res. 2008; 42(13): 3285-3304.

Chen JC, Chang NB, Chen CY, Fen CS. Minimizing the ecological risk of combinedsewer overflows in an urban river system by a system-based approach. J Environ Eng ASCE 2004; 130 (10): 1154-69.

Choi W, Deal BM. Assessing hydrological impact of potential land use change through hydrological and land use change modeling for the Kishwaukee River basin (USA). Journal of Environmental Management 2008; 88 (4): 1119-1130.

Copp JB (ed). The COST simulation benchmark- description and simulator manual. ISBN 92-894-1658-0, office for official publications of the European communities, Luxembourg, 2002.

Cox BA, Whitehead PG. Parameter sensitivity and predictive uncertainty in a new water quality model, Q2. J Environ Eng ASCE 2005; 131: 147-157.

Duh JD, Shandas V, Chang H, George LA. Rates of urbanisation and the resiliency of air and water quality. Sci Total Environ 2008; in press.

Even S, Mouchel JM, Servais P, Flipo N, Poulin M, Blanc S, Chabanel M, Paffoni C. Modelling the impacts of Combined Sewer Overflows on the river Seine water quality. Sci Total Environ 2007; 375 (1-3): 140-151.

Fu GT, Butler D, Khu ST. Multiple objective optimal control of integrated urban wastewater systems. Environ Model Softw 2008; 23: 225-234.

FWR. Urban pollution management manual, $2^{\text {nd }}$ edn. Foundation for Water Research, FR/CL0009, Marlow, UK, 1998. 
Harremoës P. Immediate and delayed oxygen depletion in rivers. Water Res 1982; 16: 1093-1098.

He H, Zhou J, Wu Y, Zhang W, Xie X. Modelling the response of surface water quality to the urbanization in Xi' an, China. Journal of Environmental Management 2008; 86 (4): 731-749.

Henze M, Grady CPL, Gujer W, Marais GvR, Matsuo T. Activated sludge model No.1. LAWQ Scientific and Technical report 1, IAWQ, London, 1986.

Hornberger GM, Spear RC. An approach to the preliminary analysis of environmental systems. Journal of Environmental Management 1981; 12: 7-18.

ITWH. Mikrocomputer in der Stadtentwässerung-Mischwasserentlastungen, Teil I, KOSIM, Version 4.1, Programmdokumentation, Institut für technischwissenschaftliche Hydrologie, Hannover, 1995 (in German).

Kafi M, Gasperi J, Moilleron R, Gromaire MC, Chebbo G. Spatial variability of the characteristics of combined wet weather pollutant loads in Paris. Water Res 2008; 42(3): 539-549.

Lau J, Butler D, Schütze M. Is combined sewer overflow spill frequency/volume a good indicator of receiving water quality impact. Urban Water 2002; 4 (2): 181-189.

Lessard P. Operational water quality management: control of stormwater dischages. $\mathrm{PhD}$ thesis. Department of Civil Engineering; Imperial College of Science, Technology and Medicine, University of London, London, 1989.

Lessard P, Beck MB. Dynamic modelling of the activated sludge process: a case study. Water Res 1993; 27 (6): 963-978.

McIntyre NR, Wagener T, Wheater HS, Chapra SC. Risk-based modelling of surface water quality: a case study of the Charles River, Massachusetts. J Hydrol 2003; 274 (1-4): 225-247. 
Olivera F, DeFee BB. Urbanization and its effect on runoff in the Whiteoak Bayou watershed, Texas. Journal of the American Water Resources Association 2007; 43 (1): $170-182$.

Rauch W, Bertrand-Krajewski JL, Krebs P, Mark O, Schilling W, Schütze M, Vanrolleghem PA. Mathematical modelling of integrated urban drainage systems. Water Sci Technol 2002; 45(3): 81-94.

Rauch W, Harremoës P. Genetic algorithms in real time control applied to minimize transient pollution from urban wastewater systems. Water Res 1999; 33 (5): 12651277.

Saltelli A, Ratto M, Tarantola S, Campolongo F. Sensitivity analysis practices: strategies for model-based inference. Reliability Engineering and System Safety 2006; 91 (10-11): 1109-1125.

Schütze M. Integrated Simulation and Optimum Control of the Urban Wastewater System. PhD thesis. Department of Civil Engineering; Imperial College of Science, Technology and Medicine, University of London, London, 1998.

Schütze M, Campisano A, Colas H, Schilling W, Vanrolleghem PA. Real time control of urban wastewater systems - where do we stand today? J Hydrol 2004; 299 (3-4): $335-348$.

Takács I, Patry GG, Nolasco D. A dynamic model of the clarification thickening process. Water Res 1991; 25 (10): 1263-1271.

Vanrolleghem PA, Benedetti L, Meirlaen J. Modelling and real-time control of the integrated urban wastewater system. Environ Model Softw 2005; 20 (4): 427-442.

Vanhooren H, Meirlaen J, Amerlinck Y, Claeys F, Vangheluwe H, Vanrolleghem PA. WEST: modelling biological wastewater treatment. Journal of Hydroinfomatics 2003; 5 (1): 27-50. 
Van Dolah RF, Riekerk GHM, Bergquist DC, Felber J, Chestnut DE, Holland AF. Estuarine habitat quality reflects urbanisation at large spatial scales in South Carolina's coastal zone. Sci Total Environ 2008; 390(1):142-54.

Wang JY, Da LJ, Song K, Li BL. Temporal variations of surface water quality in urban, suburban and rural areas during rapid urbanization in Shanghai, China. Environ Pollut 2008, 152(2): 387-393. 


\section{Figure captions}

Fig.1. Schematic representation of the integrated urban wastewater system (adapted from Fu et al., 2008). SCx represents the xth sub-catchment, and SC8 is the new development. The dashed lines show CSO discharges from the storage tanks, located at the downstream of SC2, SC4, SC6 and SC7.

Fig. 2. Simulation results for the base case scenario. (a) Rainfall series for analysis; (b) CSO discharges; (c) Treatment plant effluent concentrations; (d) DO concentrations at various reaches in the river.

Fig. 3. The impact of population size. (a) Minimum DO and maximum ammonium concentrations in the river; (b) Duration of DO and ammonium concentrations exceeding critical thresholds; (c) $95^{\text {th }}$ percentile of concentrations in treatment plant effluent. (d) Volumes of CSO and storm tank discharges;

Fig. 4. The development scales constrained by water quality standards. (a) The maximum population size in terms of various DO thresholds; (b) The maximum development area in terms of various ammonium thresholds. $\tau$ [mg/l] represents the various thresholds.

Fig. 5a-d. Cumulative distribution functions of the four parameters with regard to DOM. $S_{B}$ represents the behavioural group and $S_{N B}$ the non- behavioural group.

Fig. 6. Relationship between population size and per capita water consumption values that give rise to behaviours with regard to AMM-M. The correlation coefficient is -0.516 . 


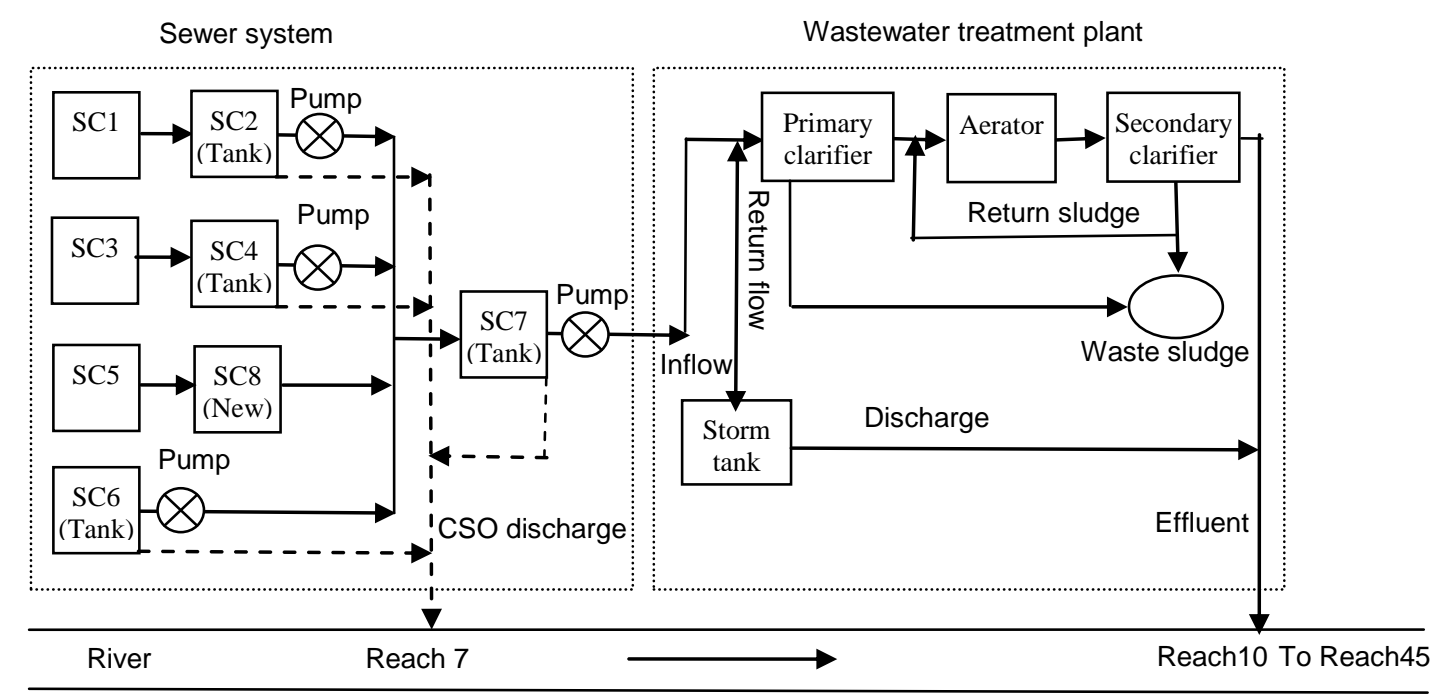

Fig.1. Schematic representation of the integrated urban wastewater system (adapted from Fu et al., 2008). SCx represents the xth sub-catchment, and SC8 is the new development. The dashed lines show CSO discharges from the storage tanks, located at the downstream of SC2, SC4, SC6 and SC7. 


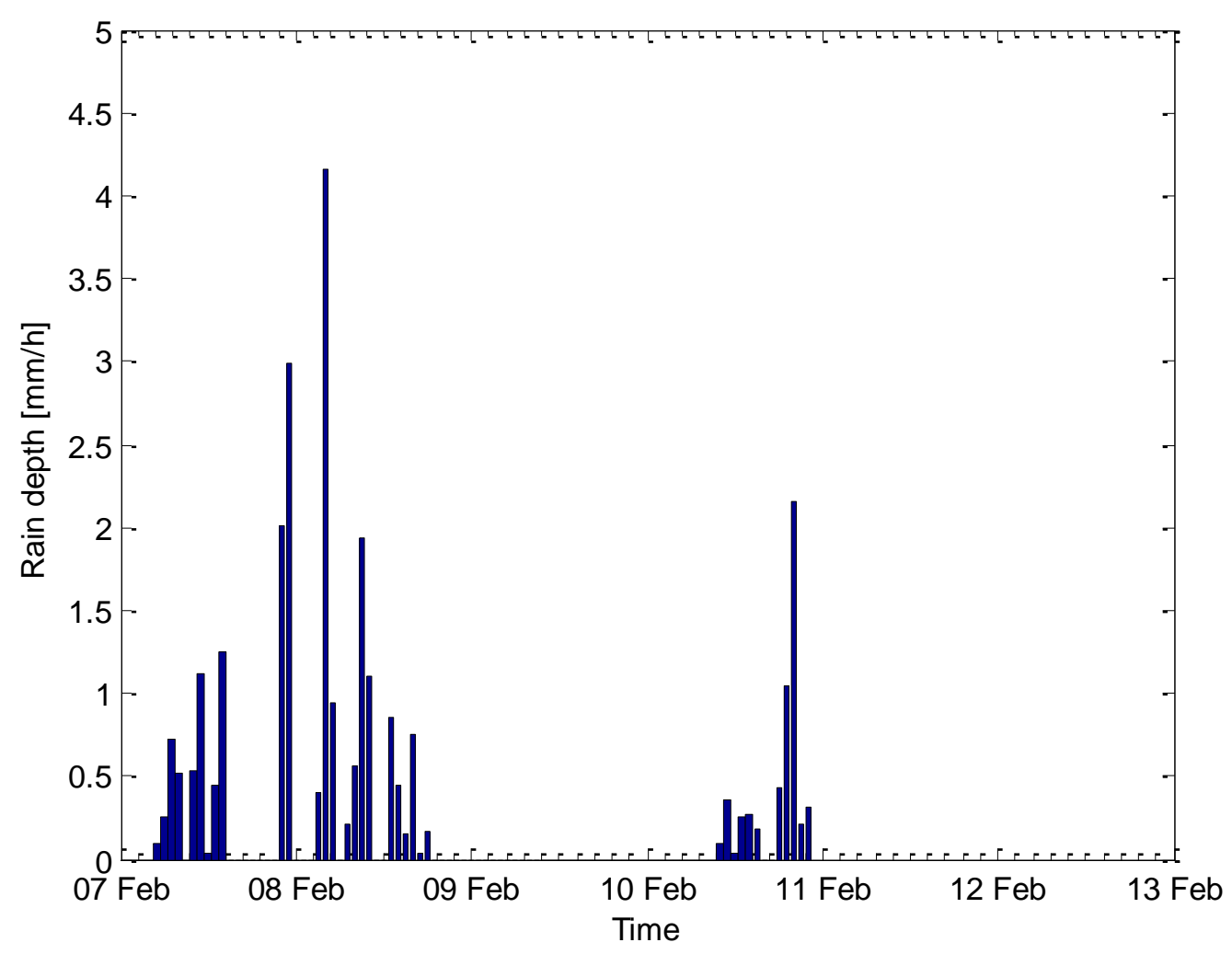

Fig. 2a. Rainfall series for analysis

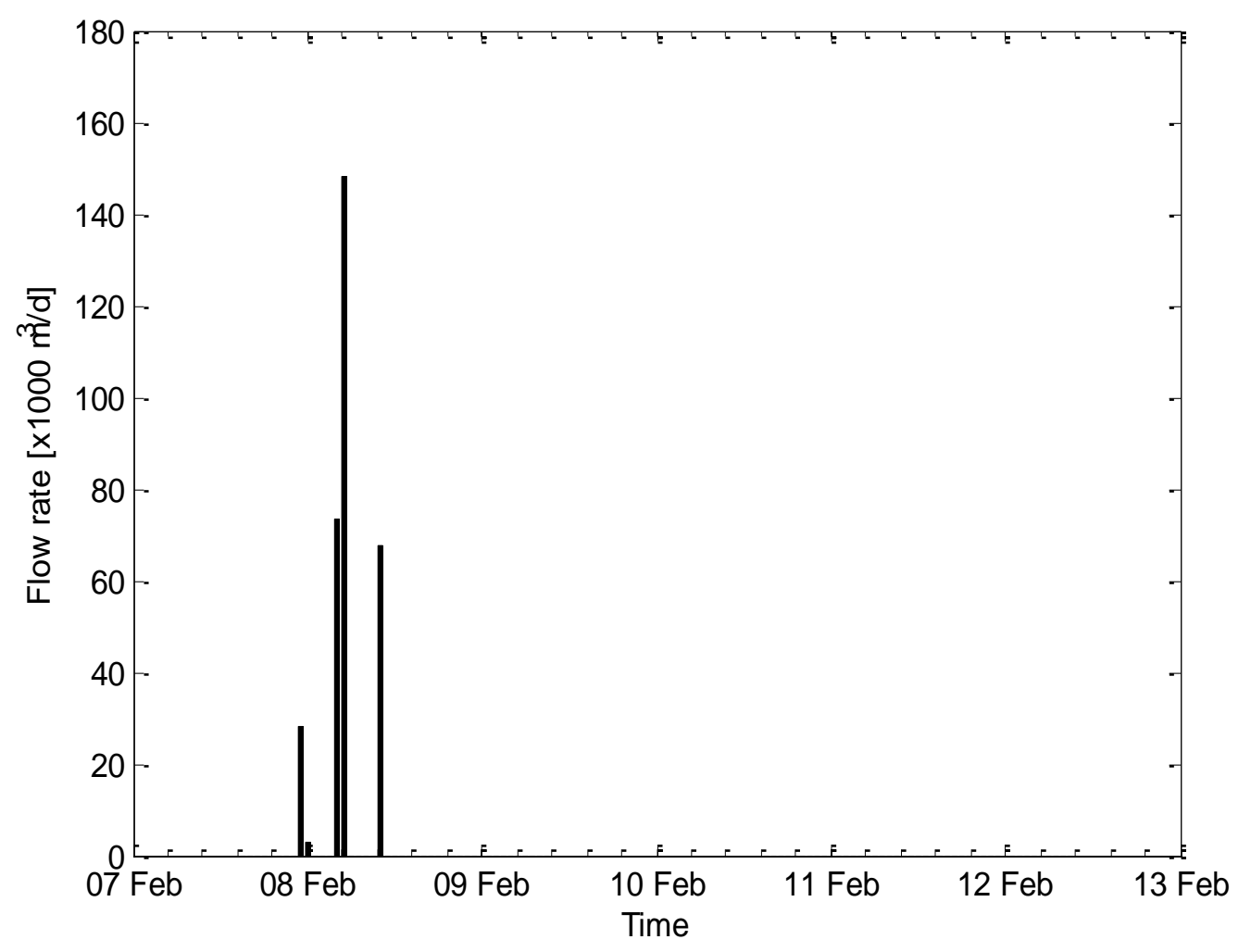

Fig. 2b. CSO discharges 


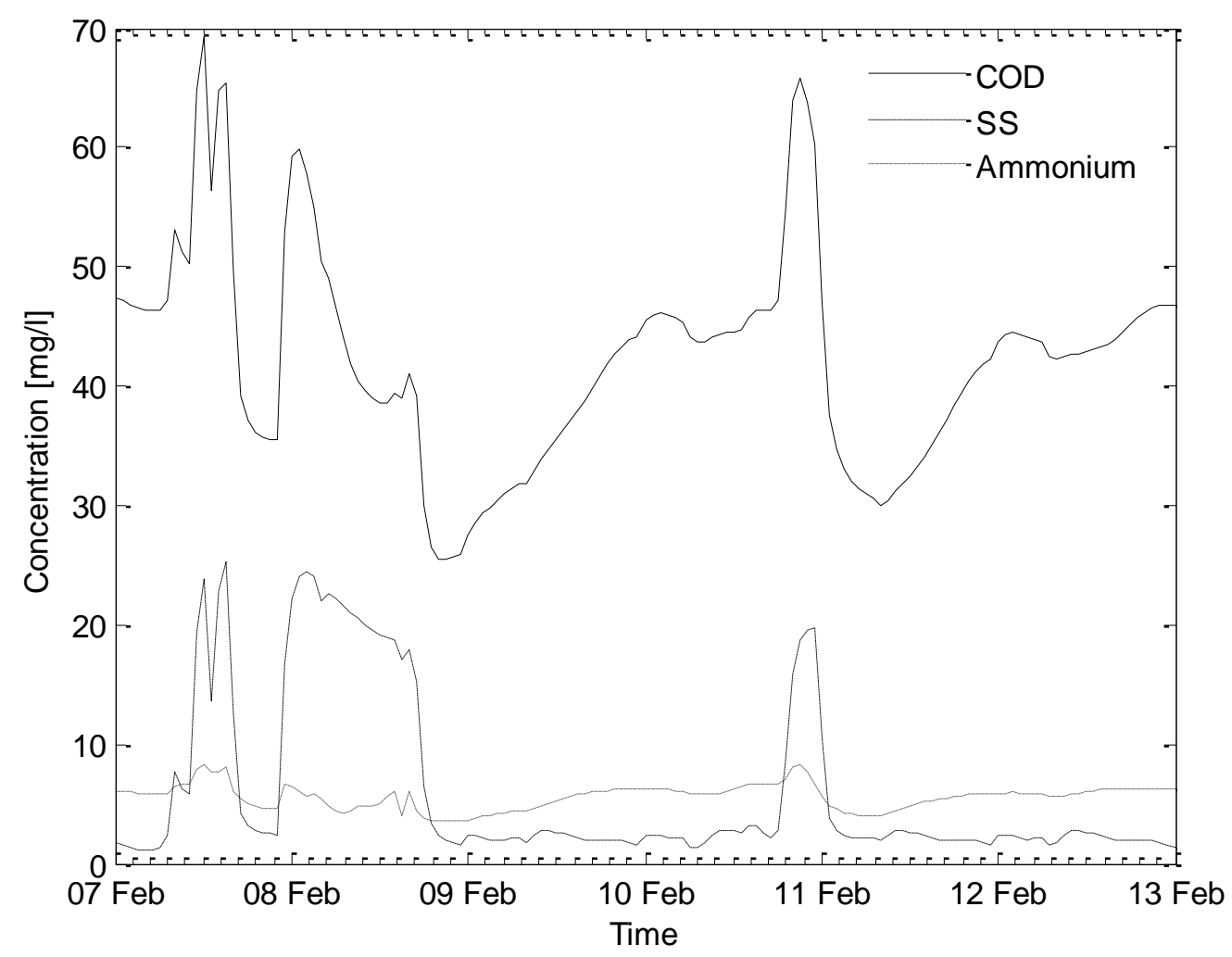

Fig. 2c. Treatment plant effluent concentrations

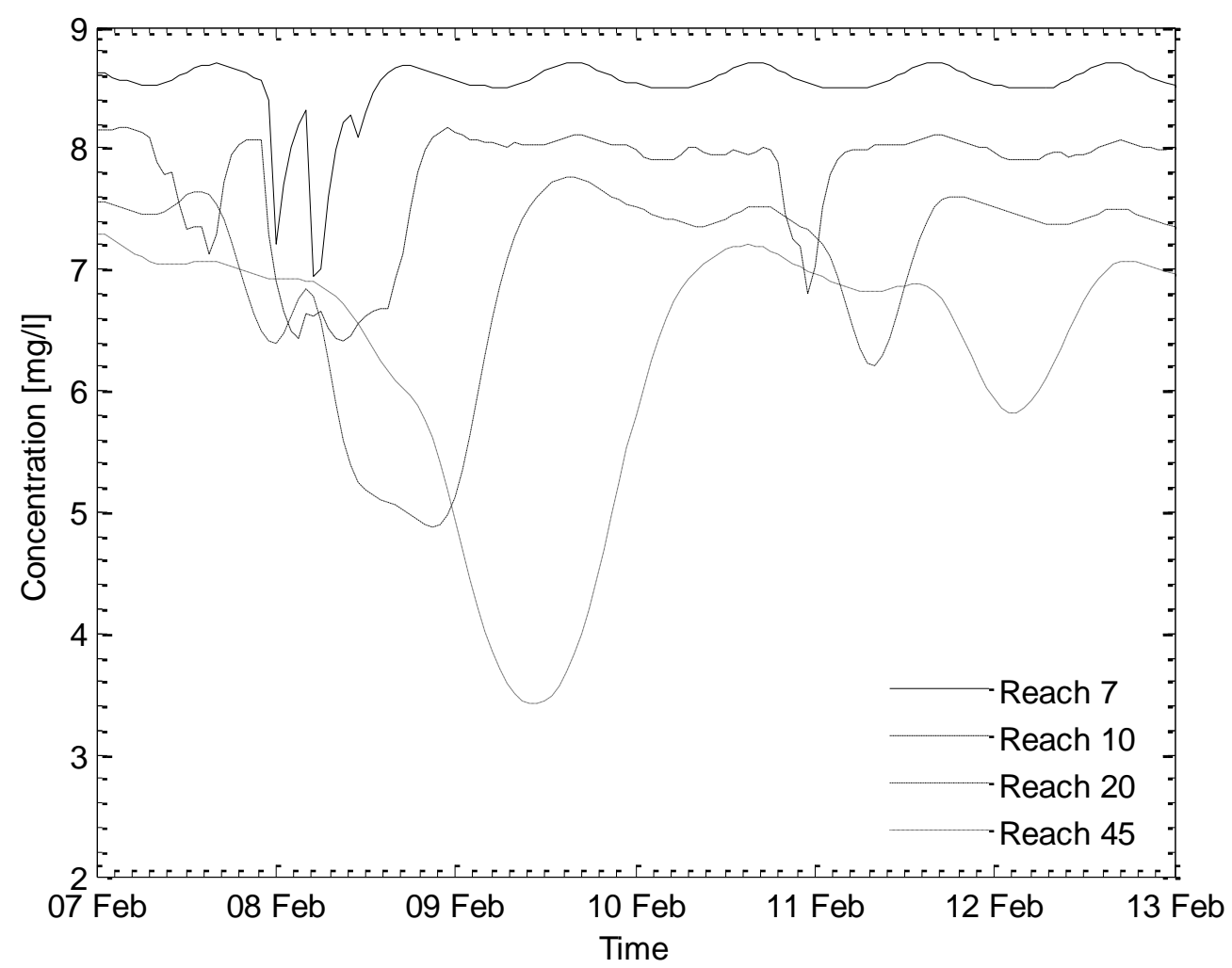

Fig. 2d. DO concentrations at various reaches in the river 


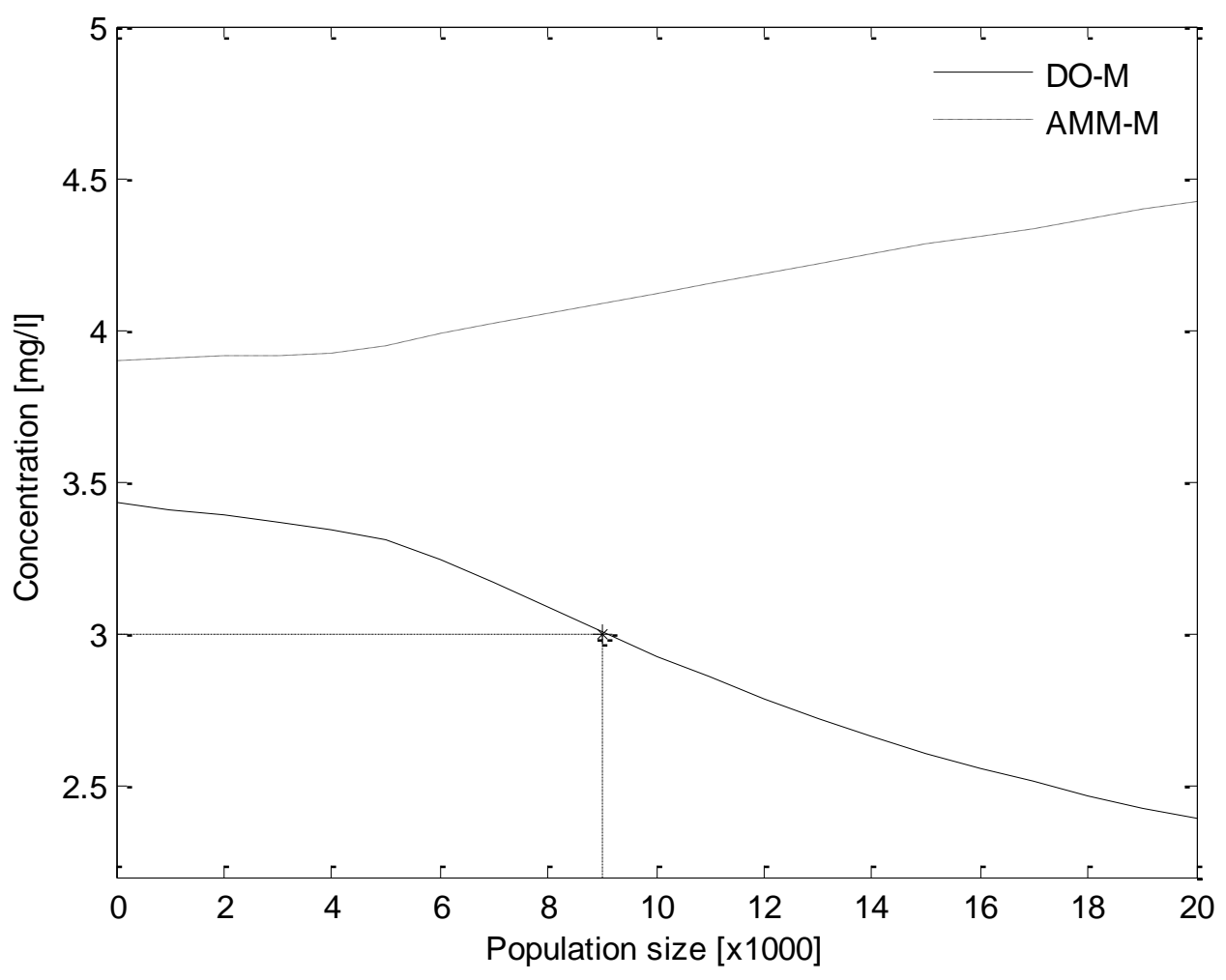

Fig. 3a. Minimum DO and maximum ammonium concentrations in the river

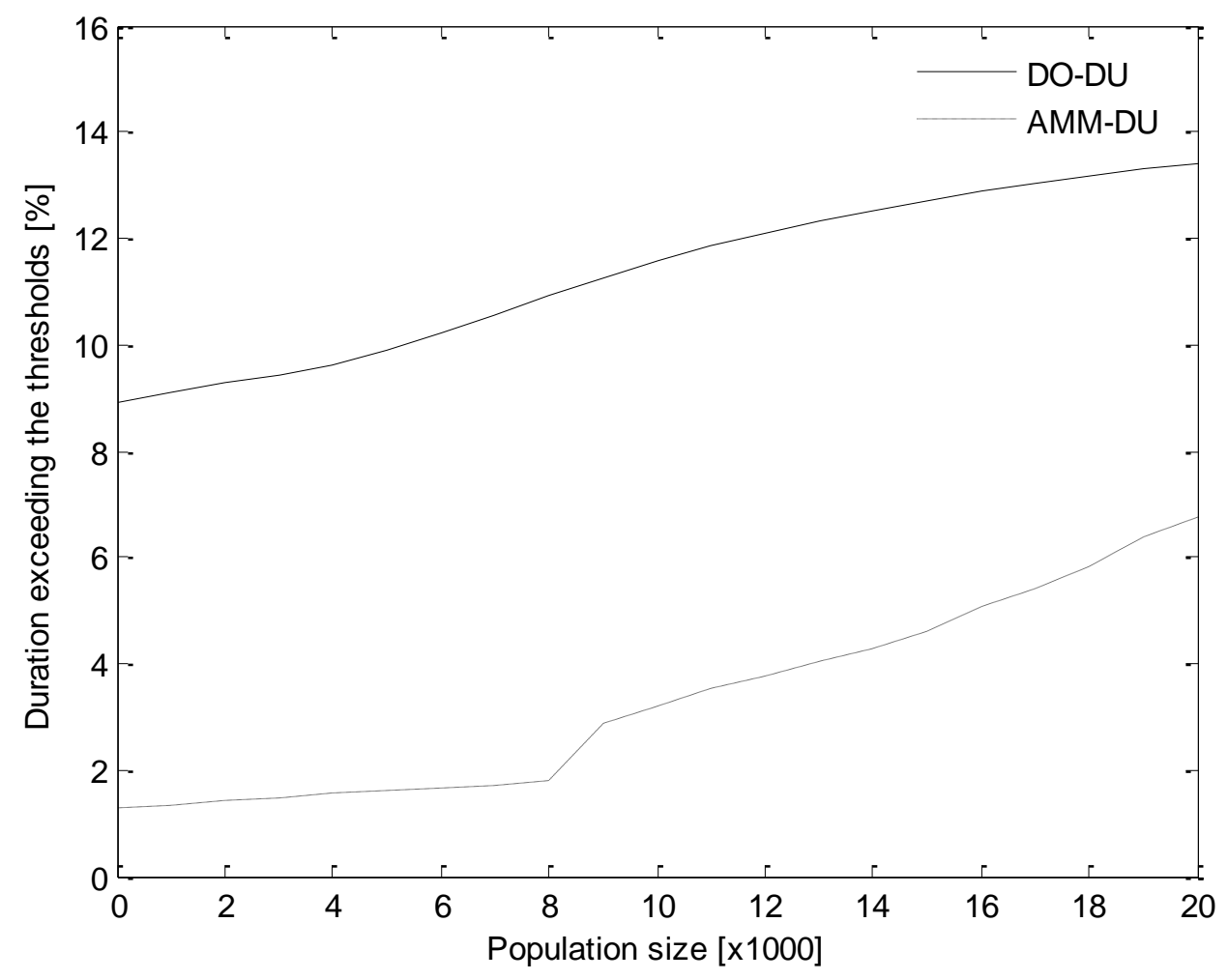

Fig. 3b. Duration of DO and ammonium concentrations exceeding critical thresholds 


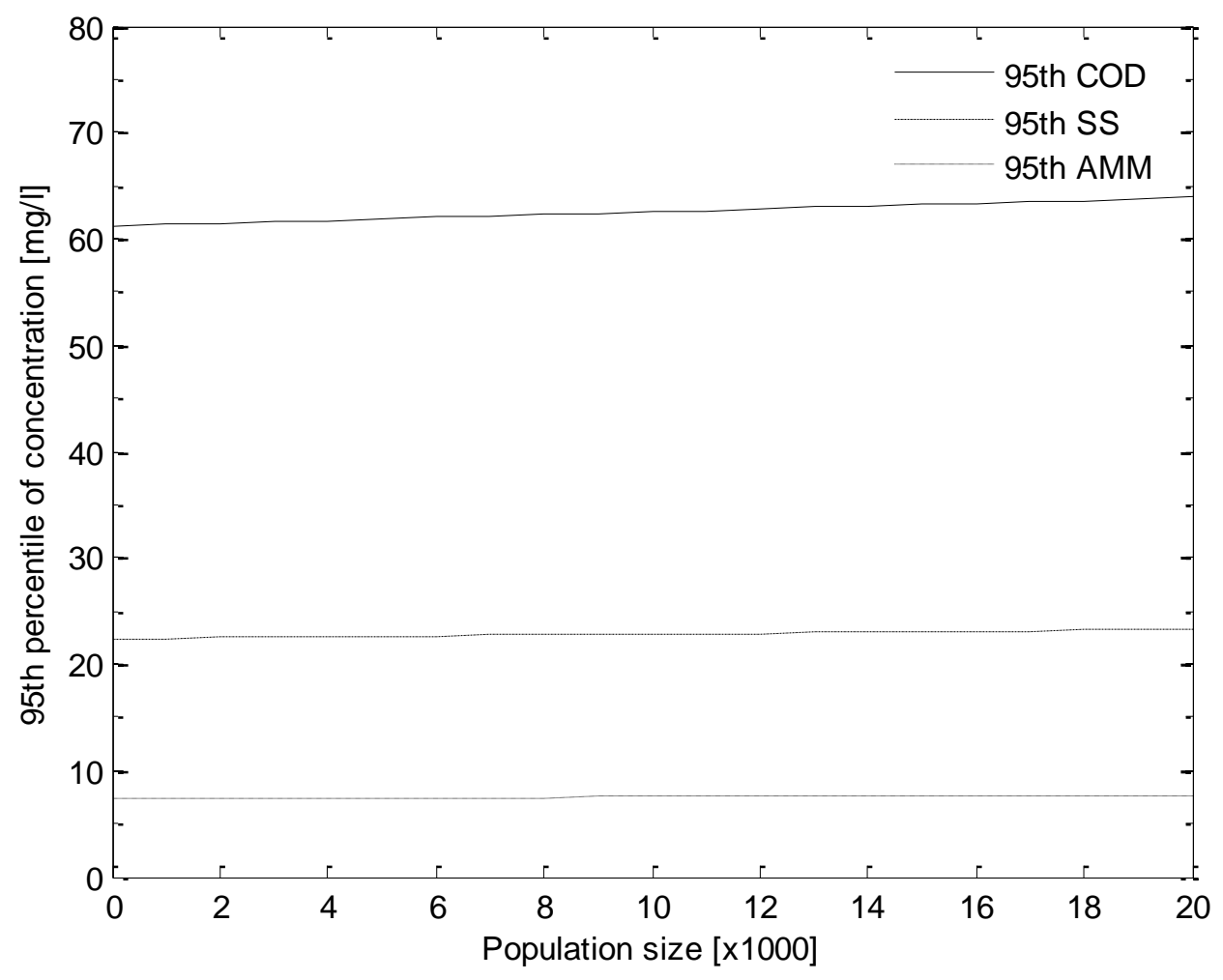

Fig. 3 c. $95^{\text {th }}$ percentile of concentrations in treatment plant effluent

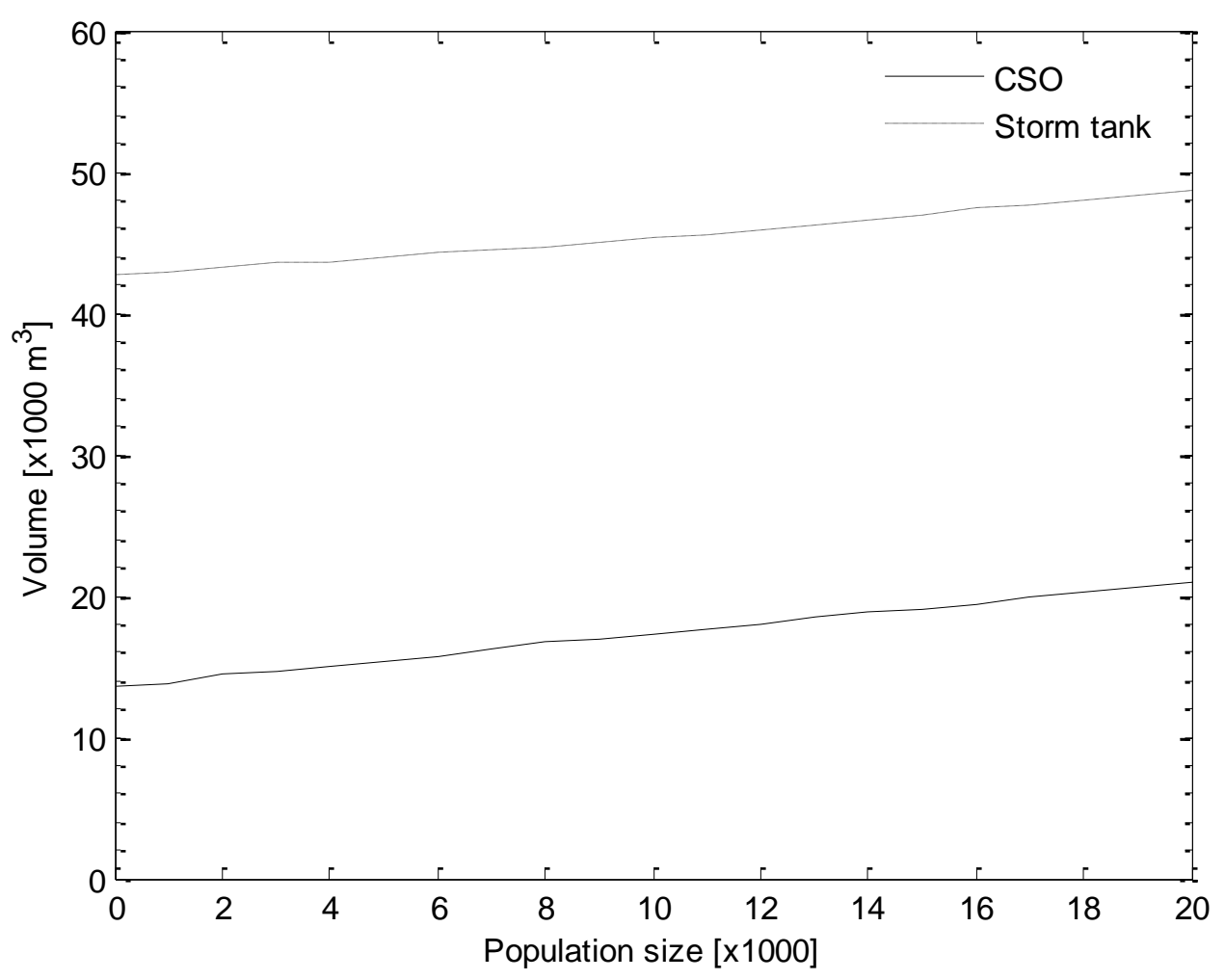

Fig. 3d. Volumes of CSO and storm tank discharges 


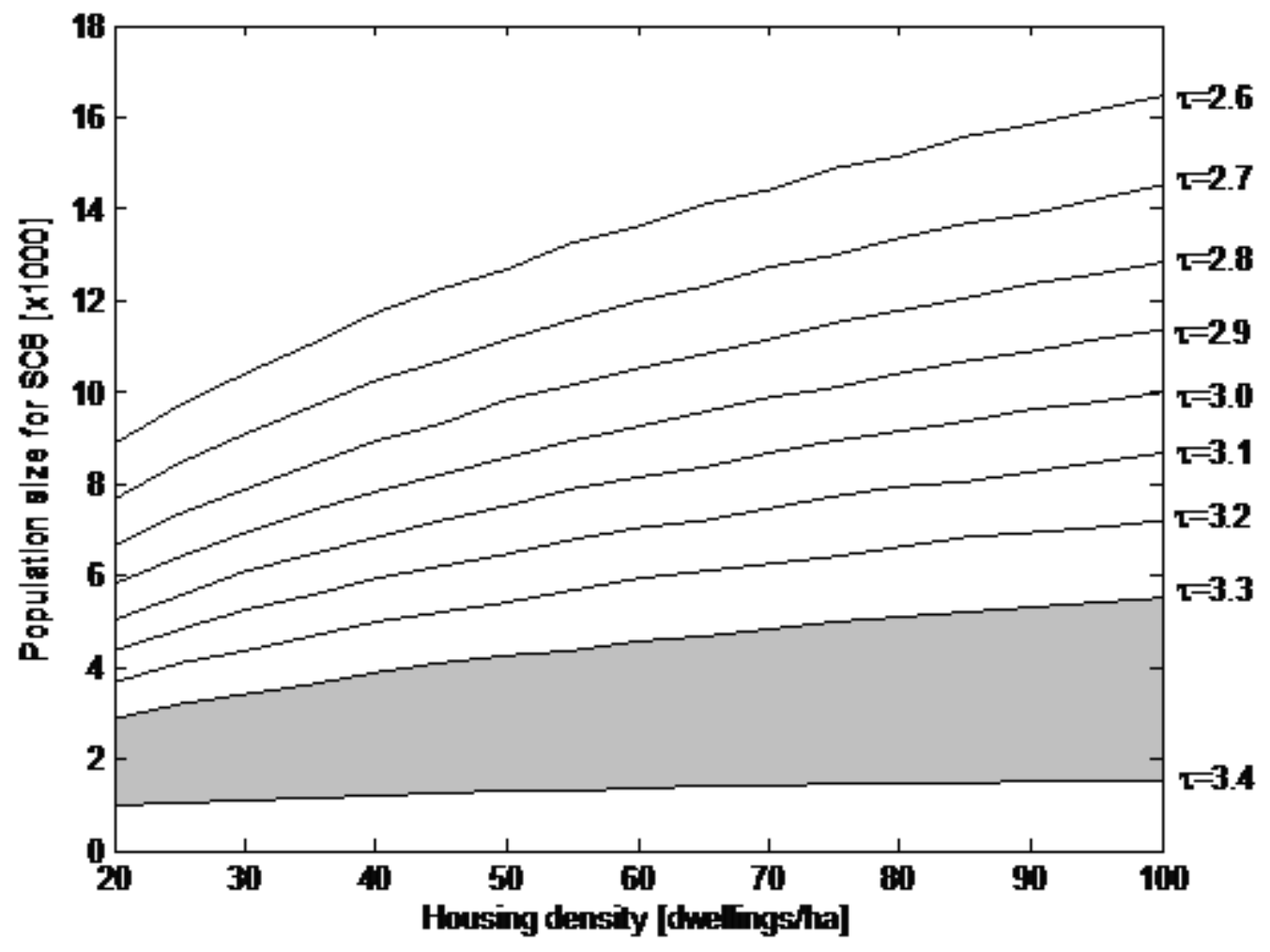

Fig. $4 \mathrm{a}$ 


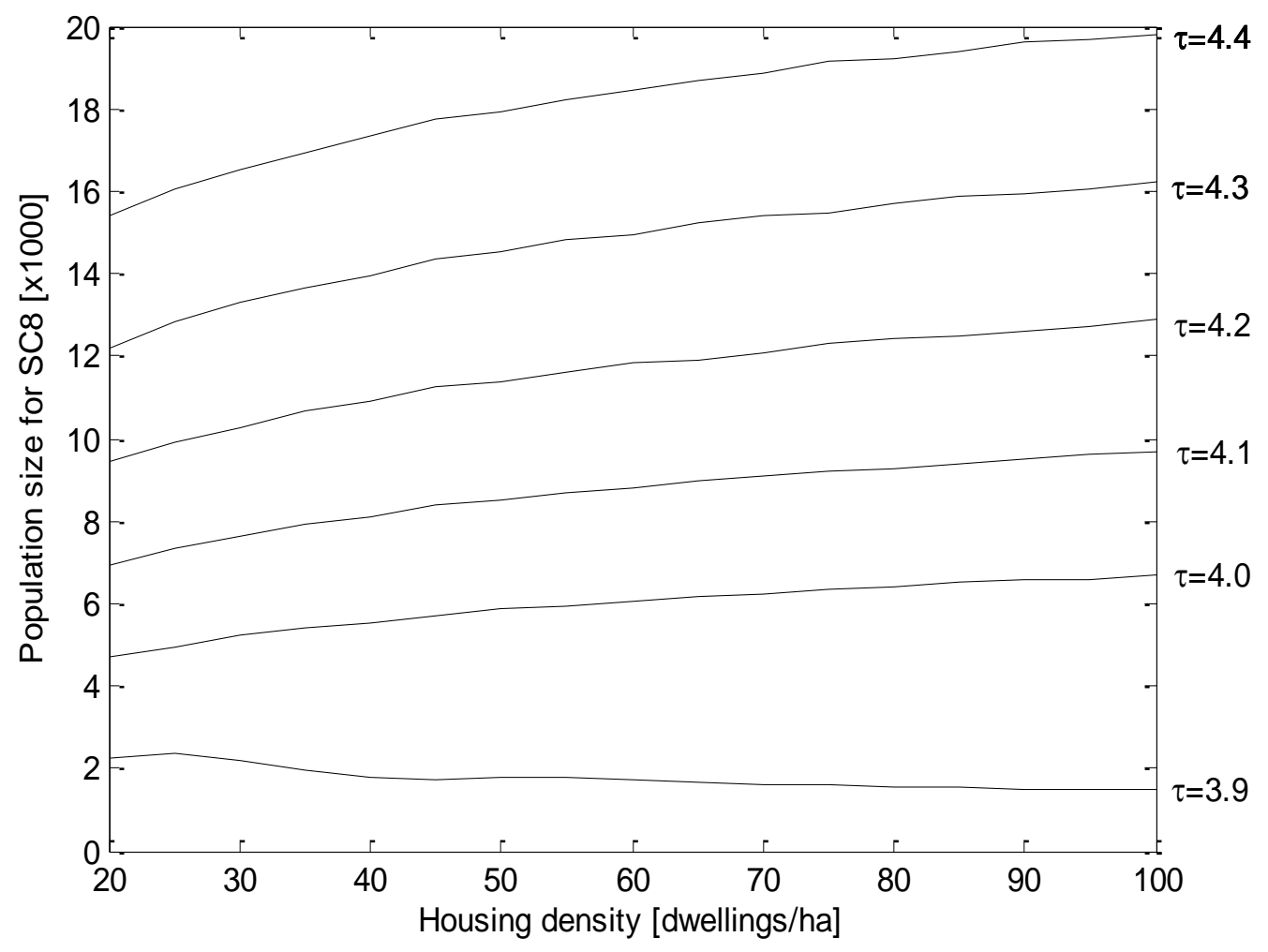

Fig. $4 b$

Fig. 4. The development scales constrained by water quality standards. (a) The maximum population size in terms of various DO thresholds; (b) The maximum development area in terms of various ammonium thresholds. $\tau[\mathrm{mg} / \mathrm{l}]$ represents the various thresholds. 


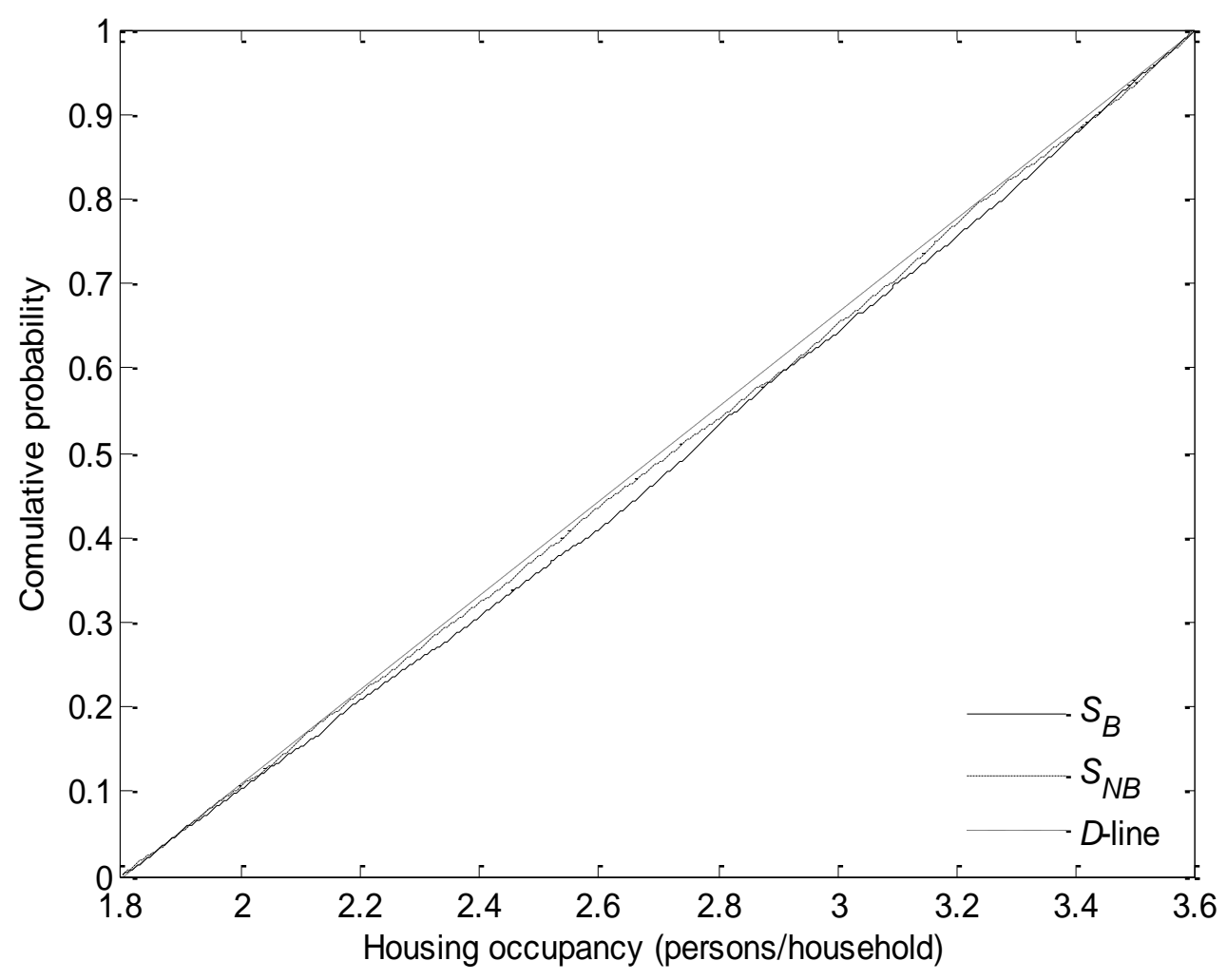

(a)

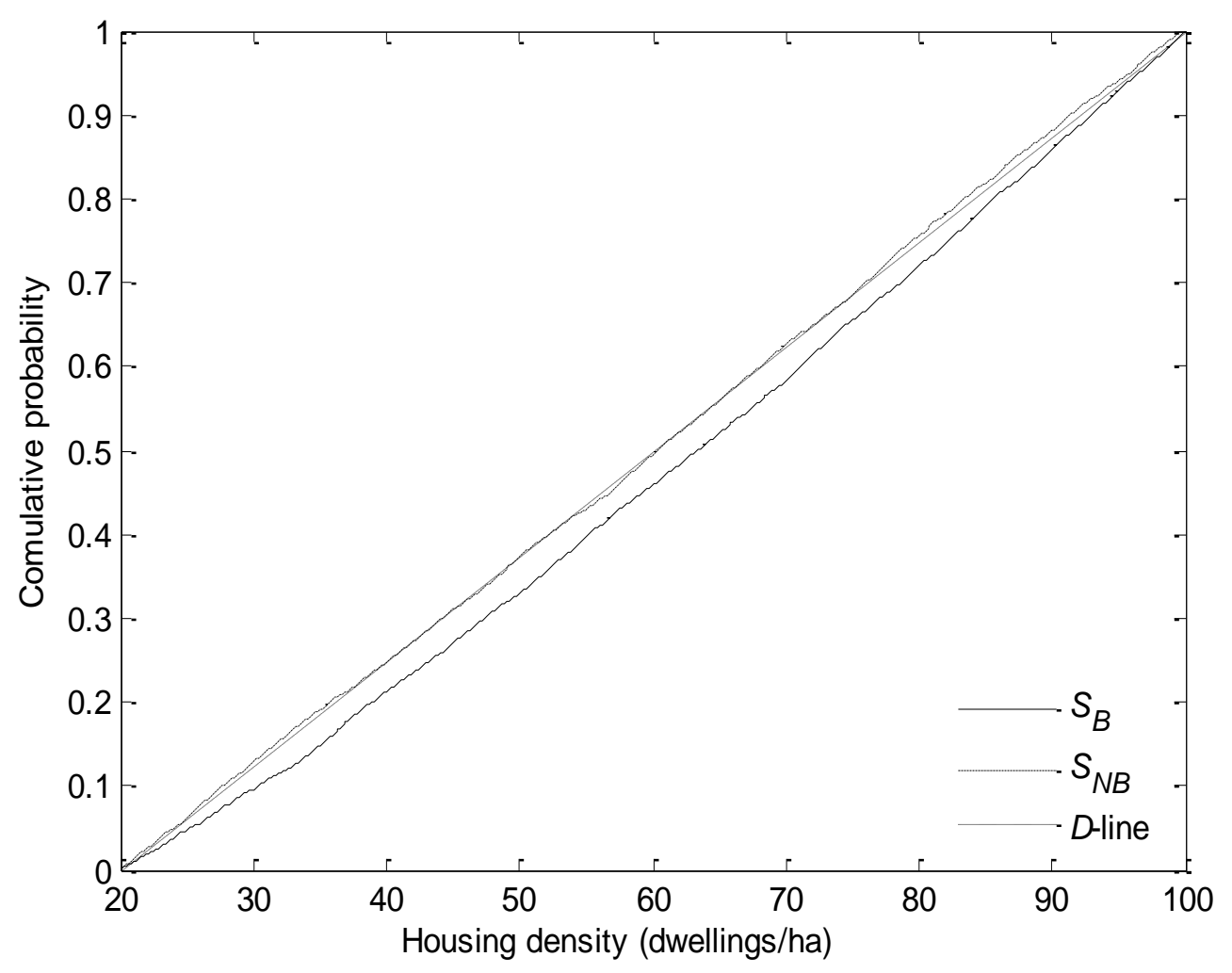

(b) 


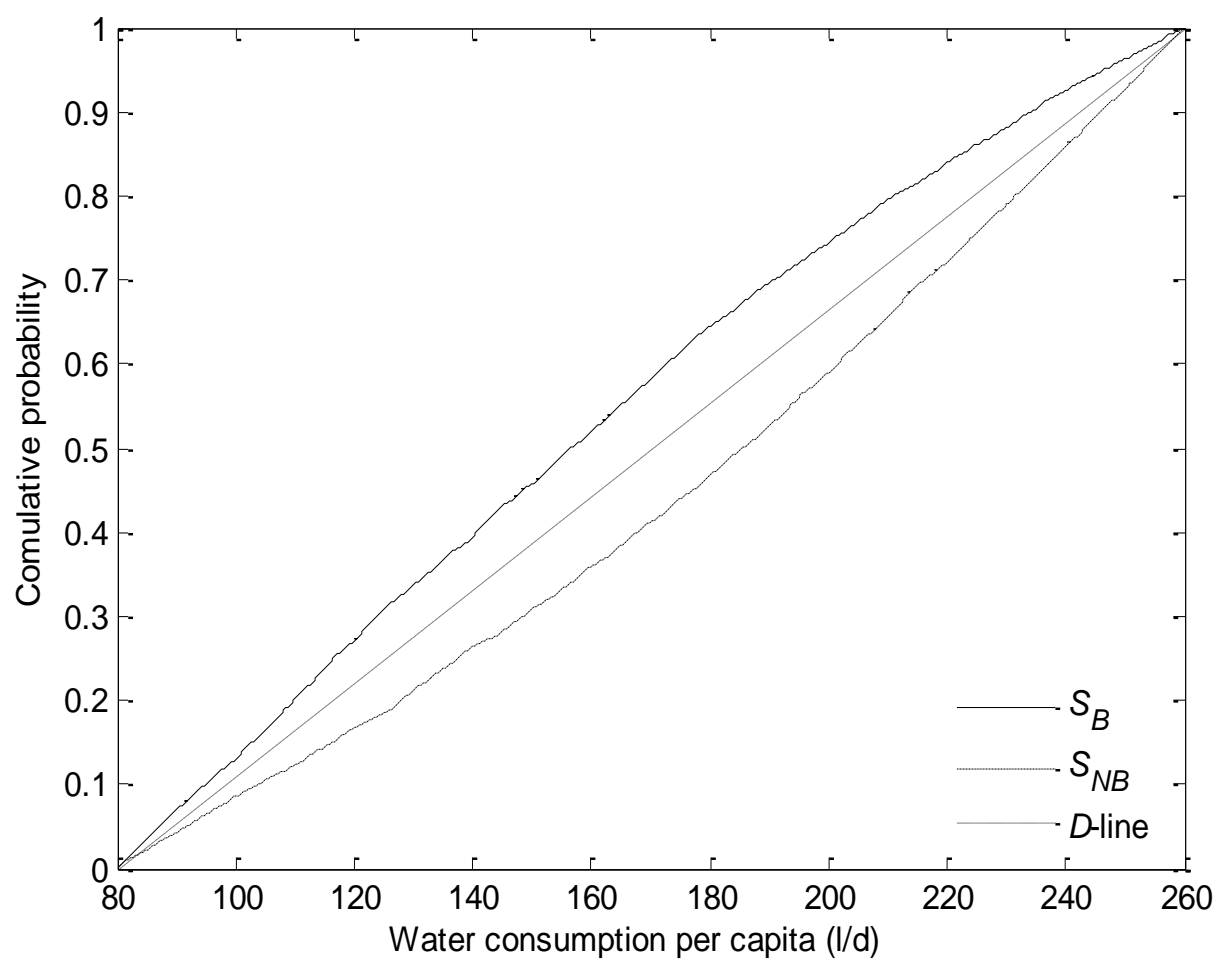

(c)

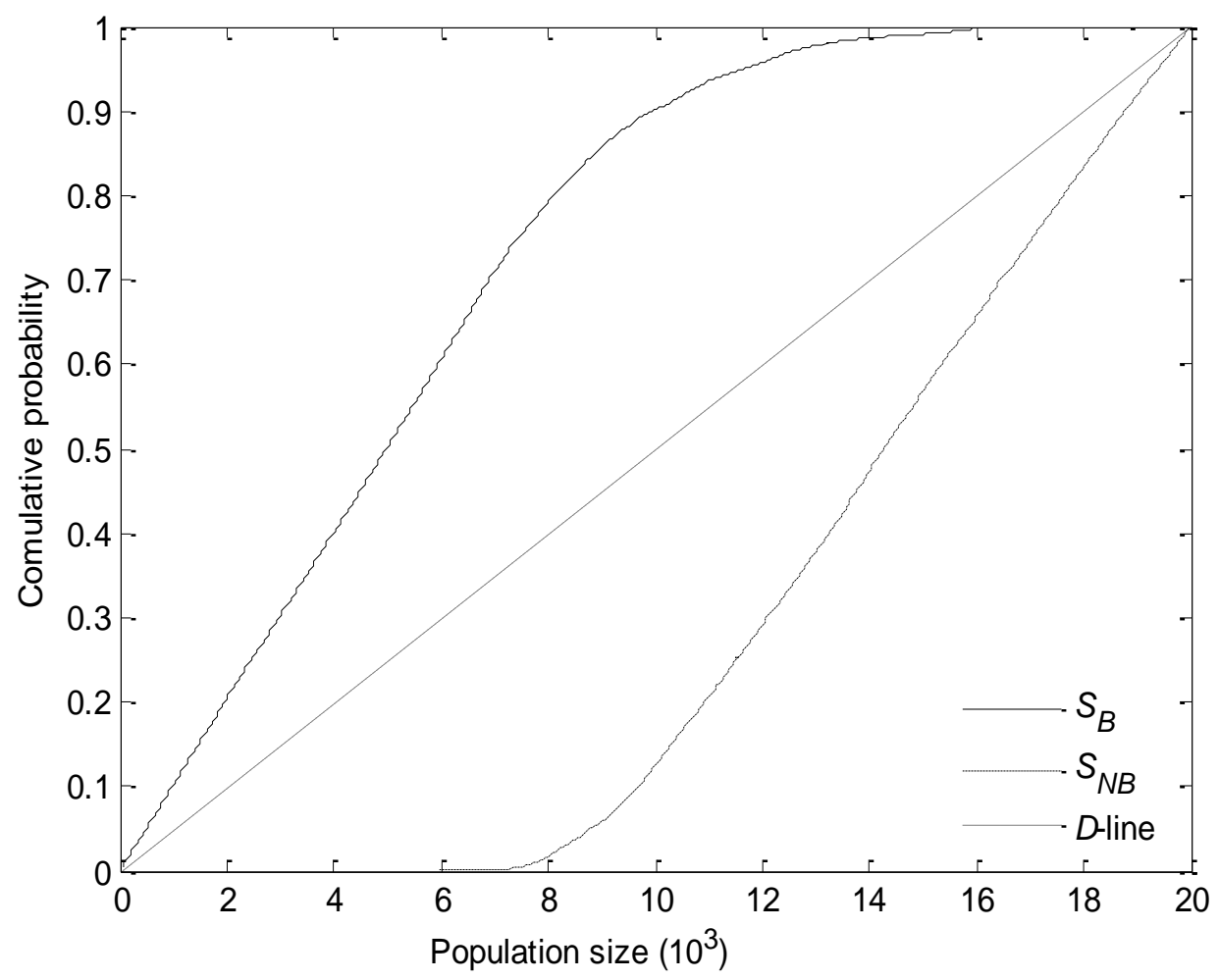

(d)

Fig. 5. Cumulative distribution functions of the four parameters with regard to DO-M. $S_{B}$ represents the behavioural group and $S_{N B}$ the non- behavioural group. 


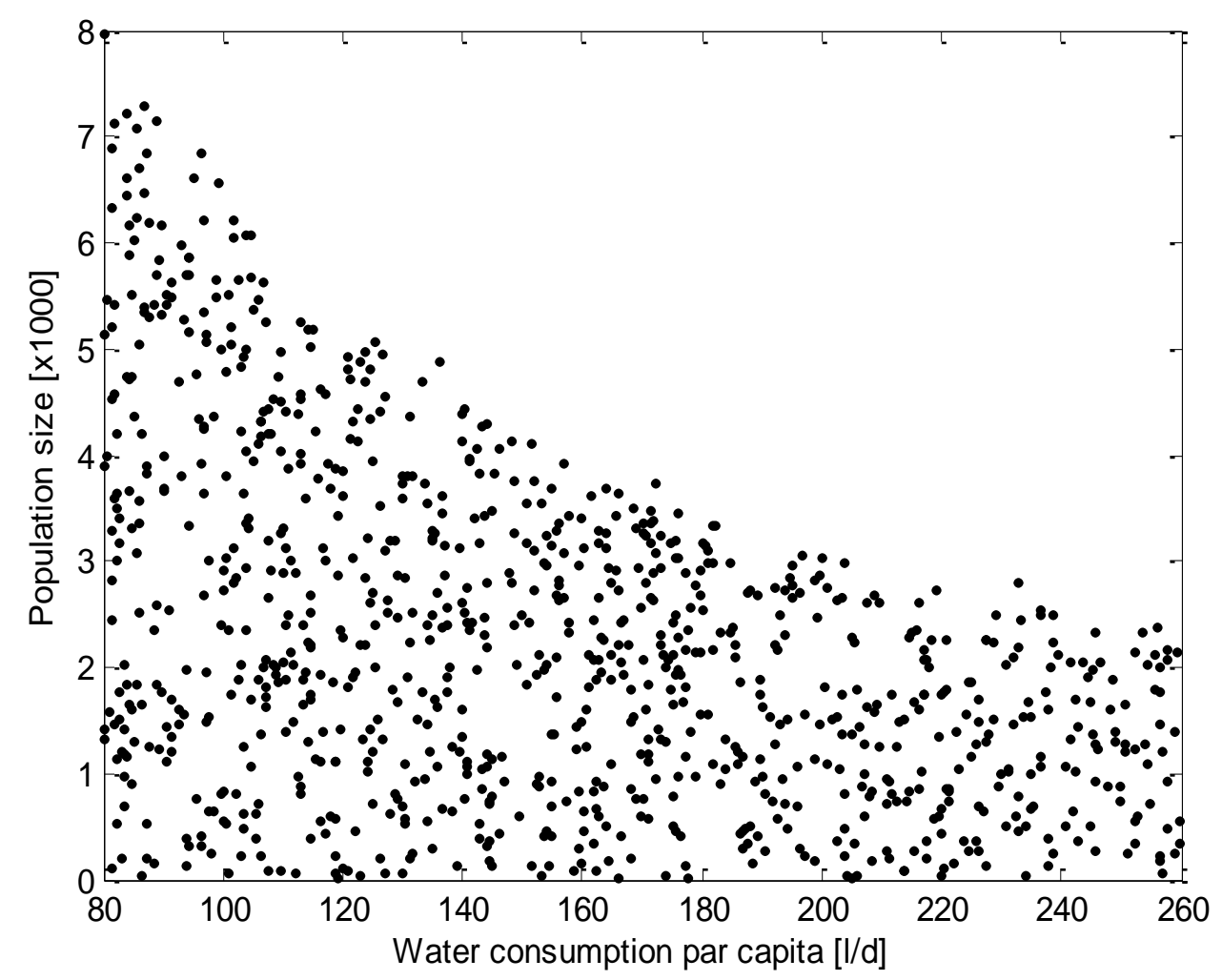

Fig. 6. Relationship between population size and per capita water consumption values that give rise to behaviours with regard to AMM-M. The correlation coefficient is 0.516 . 


\section{Table captions}

Table 1. Characteristics of the urban catchment

Table 2. Planning parameter values

Table 3. The KS statistic of each parameter for the 8 water quality indicators

Table 4. Correlations between planning parameter values giving rise to behaviours 
Table 1. Characteristics of the urban catchment

\begin{tabular}{llllllll}
\hline Sub-catchment & Area & Population & DWF & $c$ & $K$ & Tank volume \\
& {$[\mathrm{ha}]$} & & {$[\mathrm{l} / \mathrm{s}]$} & & {$[\mathrm{s}]$} & {$\left[\mathrm{m}^{3}\right]$} & \\
\hline SC1 & 66.9 & 13843 & 28.8 & 3 & 666 & - \\
SC2 & 66.9 & 13844 & 28.8 & 3 & 666 & 2800 \\
SC3 & 28.7 & 6647 & 13.9 & 3 & 235 & - \\
SC4 & 38.2 & 5867 & 12.2 & 3 & 278 & 1400 \\
SC5 & 95.5 & 17465 & 53.4 & 3 & 185 & - \\
SC6 & 95.5 & 25624 & 36.4 & 5 & 387 & 2000 \\
SC7 & 334.3 & 69493 & 144.8 & 3 & 1120 & 7000 \\
SC8 & $*$ & $0-20000$ & $*$ & 3 & 185 & - \\
\hline
\end{tabular}

*These values depend on population, housing density, housing occupancy, and water consumption, and will be calculated in the analysis. $c$ and $K$ are the parameters for the linear reservoir cascading method. 
Table 2. Planning parameter values

\begin{tabular}{lll}
\hline Parameters & Nominal value & Range \\
\hline Density [dwellings/ha] & 80 & {$\left[\begin{array}{ll}20 & 100\end{array}\right]$} \\
Occupancy [persons/household] & 2.5 & {$\left[\begin{array}{ll}1.8 & 3.6\end{array}\right]$} \\
Water consumption per capita [litre/day] & 150 & {$\left[\begin{array}{ll}80 & 260\end{array}\right]$} \\
\hline
\end{tabular}


Table 3. The KS statistic of each parameter for the 8 water quality indicators

\begin{tabular}{lcccccccc}
\hline Parameters & DO-M & AMM-M & DO-DU & AMM-DU & $9^{\text {th }}$ SS & $9^{\text {th }}$ COD & $95^{\text {th }}$ AMM & CSO volume \\
\hline Housing occupancy & 0.028 & 0.035 & 0.030 & 0.013 & 0.026 & 0.053 & 0.079 & 0.015 \\
Housing density & 0.050 & 0.045 & 0.035 & 0.026 & 0.019 & 0.044 & 0.076 & 0.025 \\
Water consumption per capita & 0.176 & 0.332 & 0.152 & 0.210 & 0.240 & 0.312 & 0.358 & 0.123 \\
Population size & 0.797 & 0.674 & 0.722 & 0.720 & 0.706 & 0.659 & 0.600 & 0.785 \\
\end{tabular}


3 Table 4. Correlations between planning parameter values giving rise to behaviours

\begin{tabular}{|c|c|c|}
\hline Objectives & Parameter* & Correlation \\
\hline DO-M & Water consumption & -0.464 \\
\hline \multirow[t]{3}{*}{ AMM-M } & Housing density & -0.202 \\
\hline & Housing occupancy & -0.120 \\
\hline & Water consumption & -0.516 \\
\hline DO-U & Water consumption & -0.372 \\
\hline AMM-DU & Water consumption & -0.428 \\
\hline $95^{\text {th }} \mathrm{SS}$ & Water consumption & -0.470 \\
\hline \multirow[t]{3}{*}{$95^{\text {th }} \mathrm{COD}$} & Housing density & -0.167 \\
\hline & Housing occupancy & -0.109 \\
\hline & Water consumption & -0.518 \\
\hline \multirow[t]{4}{*}{$95^{\text {th }} \mathrm{AMM}$} & Housing density & -0.316 \\
\hline & Housing occupancy & -0.216 \\
\hline & Housing density (water consumption) & 0.114 \\
\hline & Water consumption & -0.503 \\
\hline \multirow[t]{3}{*}{ CSO volume } & Housing density & 0.190 \\
\hline & Housing occupancy & 0.229 \\
\hline & Water consumption & -0.157 \\
\hline
\end{tabular}

$4 \quad$ *with population size otherwise indicated. 